\title{
DEVELOPMENT AND VALIDATION OF A GC-FID ASSAY FOR DETERMINATION OF FLUVASTATIN IN PHARMACEUTICAL PREPARATIONS
}

\section{Serap Saglik Aslan*, Olcay Sagirli and Lale Ersoy}

Department of Analytical Chemistry, Faculty of Pharmacy, Istanbul University, 34116 Beyazit-Istanbul, Turkey

Recebido em 1/12/08; aceito em 24/5/09; publicado na web em 30/10/09

\begin{abstract}
A gas chromatographic method has been developed for the assay of fluvastatin sodium (FLU). FLU was silylated with N,Obis(trimethylsilyl)trifluoroacetamide- $1 \%$ trimethylchlorosilane at $90{ }^{\circ} \mathrm{C}$ for $30 \mathrm{~min}$ and analysed in a DB-1 column by capillary gas chromatograph with a flame ionization detector. The method was validated. The assay was linear over the concentration range at 10.0 to $50.0 \mu \mathrm{g} \mathrm{mL}^{-1}$. The limit of detection and the limit of quantitation were 1.0 and $3.0 \mu \mathrm{g} \mathrm{mL}{ }^{-1}$, respectively. The recoveries of FLU derivatives were in the range of $99.25-99.80 \%$. In inter-day and intra-day analysis, the values of relative standard deviation (\%) and the relative mean error $(\%)$ were found between $0.20-0.80 \%$ and $-0.20-0.75 \%$, respectively. The developed method was succesfully applied to analyze the FLU content in tablet formulation. The results were statistically compared with those obtained by the official method, and no significant difference was found between the two methods. Therefore, it can be recommended for the quality control assay of FLU in pharmaceutical industry.
\end{abstract}

Keywords: fluvastatin; validation; pharmaceutical preparations.

\section{INTRODUCTION}

Fluvastatin (FLU), (3R,5S,6E)-rel-7-[3-(4-fluorophenyl)-1(1-methylethyl)-1H-indol-2-yl]-3,5-dihydroxy-6-heptenoic acid (Figure 1), is an inhibitor of 3-hydroxy-3-methylgluataryl-coenzyme A (HMG-CoA) reductase and blocks the production of cholesterol in the body. ${ }^{1-4}$ FLU is used in the treatment of hypercholestrolemia, ${ }^{5,6}$ and treatment with statin drugs decreases the risk of cardiovascular diseases, in addition to mortality. ${ }^{7}$

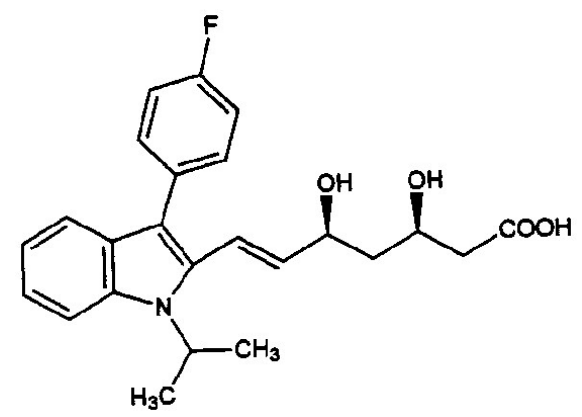

Figure 1. Chemical structure of fluvastatin

FLU has been determined by high performance liquid chromatographic methods with UV detection, ${ }^{8}$ fluorometric detection ${ }^{9-12}$ and mass spectrometric detection ${ }^{13,14}$ in human plasma. A few methods such as spectrophotometric, ${ }^{15}$ electrometric ${ }^{16,17}$ and electrophoretic $^{18,19}$ have been reported for the assay of FLU in pharmaceutical preparations. The antioxidant effects of FLU have also been studied in humans ${ }^{20-22}$ and animals. ${ }^{23,24}$

Gas chromatography/negative ion chemical ionization mass spectrometric method with pentafluorobenzylbromide has been used for determination of FLU in the human plasma. ${ }^{25}$ However, there is no gas chromatographic method with flame ionization detection (GC-FID) for determination of FLU in pharmaceutical preparations. Therefore, we have developed and validated a ra-

*e-mail: ssaglik@istanbul.edu.tr pid, simple, accurate, precise and sensitive GC-FID method with N,O-bis-(trimethylsilyl) trifluoroacetamide (BSTFA)-1\% trimethylchlorosilane (TMCS). This is the first time in the literature that this procedure was carried out. The present method provides certain advantages such as non-extraction, non-interference by excipients, being worked on easily in laboratories, as well as the economic advantage. Although GC instrument is not as common as HPLC in the pharmaceutical industry, the proposed method can be suggested as an alternative one for FLU determination in pharmaceutical preparations.

\section{EXPERIMENTAL}

\section{Chemicals and reagents}

FLU sodium and its tablets (Lescol XL $80 \mathrm{mg}$ ) were kindly supplied from Novartis (Istanbul, Turkey). N,O-bis-(trimethylsilyl) trifluoroacetamide (BSTFA) with 1\% trimethylchlorosilane (TMCS) was used as silylating reagent and purchased from Sigma (Canada, USA). Solvents and other chemicals were of analytical grade (Merck, Darmstadt, Germany).

\section{Standard solutions}

Stock solution of FLU was prepared at $0.1 \mathrm{mg} \mathrm{mL}^{-1}$ concentration in methanol and stored at $4^{\circ} \mathrm{C}$. Appropriate aliquots from stock solution were decanted to air-tight stopped glass vials and evaporated under nitrogen to obtain the residues for providing the calibration standards at 10.0, 20.0, 30.0, 40.0 and $50.0 \mu \mathrm{g} \mathrm{mL}^{-1}$ concentrations after derivatization.

\section{Derivatization}

The trimethyl silyl derivatives of standards and samples were prepared from residues obtained above, part by reacting with $100 \mu \mathrm{L}$ of BSTFA- $1 \%$ TMCS solution at $90^{\circ} \mathrm{C}$ for $30 \mathrm{~min}$ in a block heater. The resulting solutions were cooled and injected into the $\mathrm{GC}$ without removing the excess of derivativing agent, and they were kept in the air-tight glass vials below $-20{ }^{\circ} \mathrm{C} .{ }^{26}$ 


\section{Stability}

Long- and short term stability of trimethyl silyl derivative of FLU were studied over a period of $24 \mathrm{~h}$ at room temperature and one week at $4{ }^{\circ} \mathrm{C}$.

\section{Instrument and chromatographic conditions}

GC analysis were carried out using a capillary gas chromatograph (Shimadzu GC-14A, Shimadzu, Tokyo, Japan) coupled with a flame ionization detector on an DB-1 column (15 m x $0.25 \mathrm{~mm}$ I.D., $0.25 \mu \mathrm{m}$ film thickness, Shimadzu, Kyoto, Japan). The injection and detector temperatures were set at $300{ }^{\circ} \mathrm{C}$. The oven temperature was kept at $280{ }^{\circ} \mathrm{C}$. The GC-FID injected volume was $2 \mu \mathrm{L}$ and the solutions were injected in $1 / 20$ split ratio. The carrier gas was nitrogen with a pressure of $1 \mathrm{~kg} / \mathrm{cm}^{2}$. Retention times and peak areas were calculated by Class CR10 programme.

\section{Method validation}

The calibration curves were constructed with six concentrations, ranging from 10.0 to $50.0 \mu \mathrm{g} \mathrm{mL}^{-1}$. The limit of detection (LOD) and limit of quantitation (LOQ) values were calculated at a signal-to-noise ratio $(S / N)$ of 3 and 10 , respectively. ${ }^{27}$ A placebo solution was prepared and injected for determining of the method specificity. To determine the precision of the method, intra-day and inter-day analyses were carried out by analysing FLU samples at five concentrations; 10.0, 20.0, 30.0, 40.0 and $50.0 \mu \mathrm{g} \mathrm{mL}^{-1}$. The values for the relative standard deviation (RSD) and the relative mean error (RME) were calculated for FLU solutions. Accuracy was assessed using 6 determinations of each 5 concentration levels (10.0, 20.0, 30.0, 40.0 and $\left.50.0 \mu \mathrm{g} \mathrm{mL}^{-1}\right)$. Accuracy was reported as percent recovery by the assay of known added of amount of analyte in the sample. ${ }^{27}$

The robustness of the method was investigated by small changes in these parameters; temperature of the injector, temperature of the detector, oven temperature and injected volume at $30.0 \mu \mathrm{g} \mathrm{mL}^{-1}$ concentration of FLU.

\section{Assay procedure for tablets}

Ten tablets were weighed and powdered. An accurately weighed portion of the powdered tablets, equivalent to about $10 \mathrm{mg}$ of FLU sodium was shaken mechanically with $50 \mathrm{~mL}$ methanol for $30 \mathrm{~min}$ and diluted to $100 \mathrm{~mL}$ with the same solvent, mixed and filtered. Appropriate aliquots from the filtrate were decanted to air-tight stopped glass vials and evaporated under nitrogen to obtain the residues for providing at $30.0 \mu \mathrm{g} \mathrm{mL}-1$ concentration after derivatization. For the selectivity of assay, titanium dioxide, yellow iron oxide and red iron oxide were analysed as tablet excipients including no any organic one.

\section{Reference method}

Liquid chromatographic analyses were performed on a thermo separation products liquid chromatograph (TX, USA) which consisted of a P4000 solvent delivery system equipped with a rheodyne injection valve with a $20 \mu \mathrm{L}$ loop, a UV3000 detector and an SN4000 automation software system. The analyses were carried out using a C18 column with a flow rate of $2.0 \mathrm{~mL} \mathrm{~min}{ }^{-1}$. $54 \%$ solution A [pH 7.2 buffer solution:methanol (3)-acetonitrile (2); $87.5: 12.5$ ] and $46 \%$ solution B [methanol (3)-acetonitrile (2):pH 7.2 buffer solution; $87.5: 12.5$ ] were used as mobile phase. UV-detection was at $305 \mathrm{~nm}^{28}$

\section{RESULTS AND DISCUSSION}

\section{Derivatization procedure}

The optimum derivatization conditions were set up to obtain trimethyl silyl derivative of FLU with BSTFA-1\% TMCS solution for quantitative analyses. Different times and temperatures of heating were verified, ranging from 15.0 to $60.0 \mathrm{~min}$, and 30 to $120^{\circ} \mathrm{C}$, respectively. It was verified based on the experimental results presented in Figure 2 that the best condition for derivatization step was heating at $90{ }^{\circ} \mathrm{C}$ for $30 \mathrm{~min}$. After the experienced of adding the range of 50 to 150 $\mu \mathrm{L}$ of reagent solution, a better yield of trimethyl silyl derivative was obtained with $100 \mu \mathrm{L}$ of that solution. The derivatization reaction did not take long, and no extraction with a toxic solvent was necessary in the procedure. The derivatives were stable for one week at $4{ }^{\circ} \mathrm{C}$. Their stability was then investigated for $24 \mathrm{~h}$ at room temperature. There was no significant difference in the peak areas of FLU (Table 1).

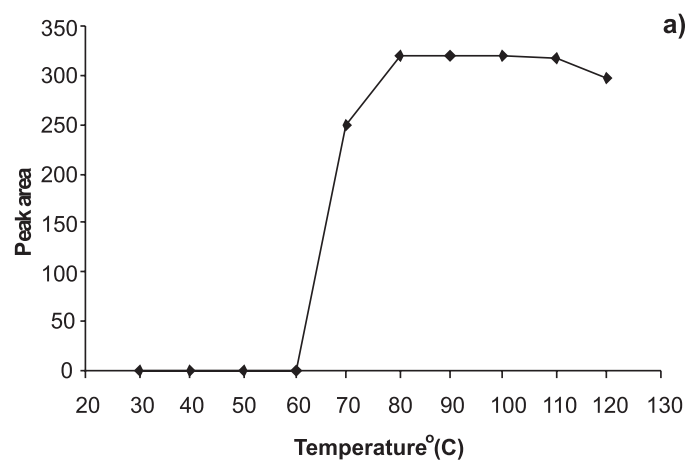

a)

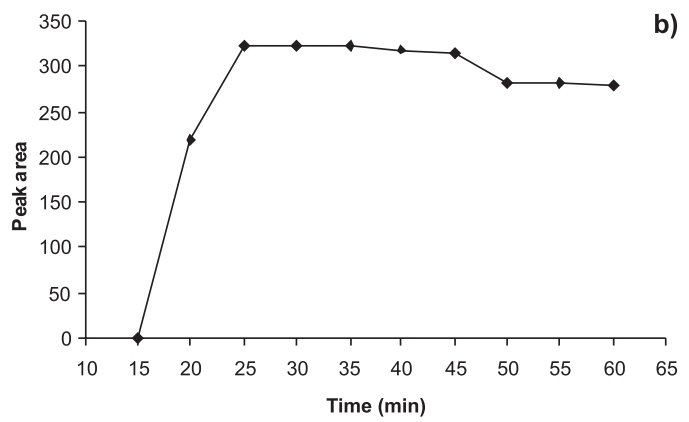

Figure 2. a) Effect of derivatization temperature on peak area of FLU (30 $\left.\left.\mu \mathrm{g} m L^{-1}\right) ; b\right)$ effect of derivatization time on peak area of $F L U\left(30 \mu \mathrm{g} \mathrm{mL^{-1 }}\right)$

Table 1. Stability data for FLU derivatives at $30 \mu \mathrm{g} \mathrm{mL}^{-1}$ concentration ( $\mathrm{n}=6$ per test)

\begin{tabular}{lcc}
\hline Test & Recovery $(\%)$ & RSD $^{*}(\%)$ \\
\hline 24 h, room temperature & 99.73 & 0.60 \\
One week, $-4{ }^{\circ} \mathrm{C}$ & 99.33 & 0.44 \\
\hline
\end{tabular}

* RSD $=$ relative standard deviation

\section{Chromatographic conditions}

In the literature, $\left[{ }^{18} \mathrm{O}_{2}\right]$-FLU has been prepared from unlabelled FLU and used as an internal standard for gas chromatography/mass spectrometry under negative ion chemical ionization conditions for determination of FLU in human plasma. ${ }^{25}$ In that procedure, sample preparation took long time, whereas internal standard addition was not necessary in our study and sample preparation was simply, fast, and with good in 
reproducibility. The FLU typical chromatogram (standard solution, 30 $\mu \mathrm{g} \mathrm{mL}^{-1}$ ) is shown in Figure 3 and its retention time was $6.0 \mathrm{~min}$ with good peak shape. The FLU amount was calculated using the peak areas.

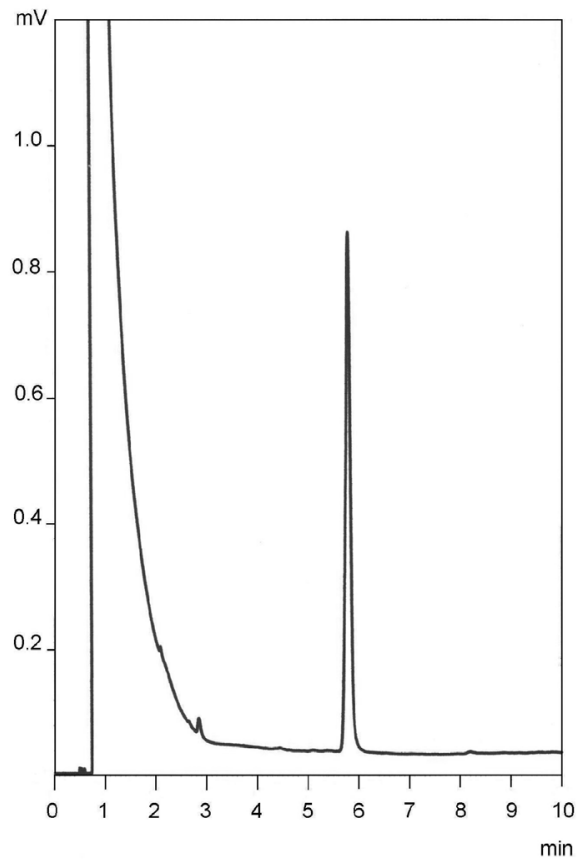

Figure 3. Gas chromatogram of FLU standard solution $\left(30 \mu \mathrm{g} \mathrm{mL^{-1 } )}\right.$

\section{Method validation}

Calibration graphs were constructed by plotting the values of the peak area against concentrations. A linear correlation was obtained over the range of 10.0-50.0 $\mu \mathrm{g} \mathrm{mL}^{-1}$ concentrations. The regression equation was found to be $\mathrm{A}=7.040 \mathrm{C}+106.8 ; \mathrm{r}=0.9996$ (A: area, $\mathrm{C}$ : concentration; $\left.\mu \mathrm{g} \mathrm{mL}^{-1}\right)$. Standard deviation on slope $(\mathrm{Sb})$ was 0.087 and on intercept (Sa) was 2.691. LOD was $1.0 \mu \mathrm{g} \mathrm{mL}^{-1}$ at a signalto-noise ratio $(S / N)$ of 3 , and LOQ was found to be $3.0 \mu \mathrm{g} \mathrm{mL} \mathrm{mL}^{-1}$ at signal-to-noise ratio $(S / N)$ of 10 . The sensitivity of this study was similar when compared with those of in literature findings for the assay of FLU in pharmaceutical preparations. ${ }^{15-19}$ No peak was found at the retention time of FLU in placebo solution. The good recoveries of FLU were in the range of $99.25-99.80 \%$ in determining of the accuracy of the method (Table 2). In intra-day and inter-day analyses, the values of RSD (\%) and RME (\%) were found to be between $0.20-0.80 \%$ and $-0.20-0.75 \%$ for FLU solutions, respectively (Table $3)$. These data indicate that the assay method is precise within the same day and on different days. The robustness of the method was investigated in view of temperatures of injection, detector and oven, in addition to the injected volume. There was no significant difference in the results obtained.

\section{Assay procedure for tablets}

The developed method was applied to the determination of FLU in tablets. The drug content in tablet was calculated from the regression equation of the calibration curve. The statistical values were compared with those obtained by the reference method, ${ }^{28}$ and there was no significant difference between them (Table 4). The selectivity of assay was determined by analysing of interferences by the excipients; titanium dioxide, yellow iron oxide and red iron oxide; no peaks were present in the chromatogram at the retention time of FLU.
Table 2. Results from recovery studies of FLU (n=6)

\begin{tabular}{lccc}
\hline \multicolumn{2}{c}{ Concentration $\left(\mu \mathrm{g} \mathrm{mL}^{-1}\right)$} & & \\
\cline { 1 - 2 } Added & Found $\left(\mathrm{mean} \pm \mathrm{SD}^{*}\right)$ & Recovery $(\%)$ & $\mathrm{RSD}^{* *}(\%)$ \\
\cline { 1 - 2 } 20.0 & $9.96 \pm 0.06$ & 99.60 & 0.60 \\
20.0 & $19.85 \pm 0.14$ & 99.25 & 0.71 \\
30.0 & $29.94 \pm 0.09$ & 99.80 & 0.30 \\
40.0 & $39.74 \pm 0.15$ & 99.40 & 0.38 \\
50.0 & $49.87 \pm 0.17$ & 99.74 & 0.34 \\
\hline
\end{tabular}

" $\mathrm{SD}=$ standard deviation. ${ }^{* *} \mathrm{RSD}=$ relative standard deviation

Table 3. Intra-day and inter-day variabilities of FLU ( $n=6)$

\begin{tabular}{lcccc}
\hline $\begin{array}{l}\text { Proposed } \\
\text { method }\end{array}$ & Added & $\begin{array}{c}\text { Concentration } \\
\left.(\mu \mathrm{g} \mathrm{mL})^{-1}\right)\end{array}$ & $\begin{array}{c}\mathrm{RSD}^{* *} \\
(\%)\end{array}$ & $\begin{array}{c}\mathrm{RME}^{* * * *} \\
(\%)\end{array}$ \\
\hline Fntraday & 10.0 & $9.97 \pm 0.06$ & 0.60 & -0.30 \\
& 20.0 & $19.95 \pm 0.13$ & 0.65 & -0.25 \\
& 30.0 & $29.94 \pm 0.10$ & 0.33 & -0.20 \\
& 40.0 & $39.70 \pm 0.08$ & 0.20 & -0.75 \\
& 50.0 & $49.85 \pm 0.15$ & 0.30 & -0.30 \\
Interday & 10.0 & $9.94 \pm 0.08$ & 0.80 & -0.60 \\
& 20.0 & $19.88 \pm 0.14$ & 0.70 & -0.60 \\
& 30.0 & $29.90 \pm 0.09$ & 0.30 & -0.33 \\
& 40.0 & $39.72 \pm 0.11$ & 0.28 & -0.70 \\
& 50.0 & $49.82 \pm 0.19$ & 0.38 & -0.36 \\
\hline
\end{tabular}

${ }^{*} \mathrm{SD}=$ standard deviation. ${ }^{* *} \mathrm{RSD}=$ relative standard deviation. ${ }^{* * *} \mathrm{RME}=$ relative mean error

Table 4. Determination of FLU in tablets labelled containing $80 \mathrm{mg}$ of FLU per tablet $(n=6)$

\begin{tabular}{lcc}
\hline Statistical value & Proposed method & Reference method ${ }^{27}$ \\
\hline Means amount of drug found & & \\
(mg per tablet) & 79.09 & 79.72 \\
SD* $^{*}$ & 0.38 & 0.68 \\
RSD $^{* *}(\%)$ & 0.48 & 0.85 \\
$\%$ Recovery & 98.86 & 99.65
\end{tabular}

${ }^{*} \mathrm{SD}=$ standard deviation. ${ }^{* *} \mathrm{RSD}=$ relative standard deviation

\section{CONCLUSION}

A GC-FID method for BSTFA-1\% TMCS derivatized FLU determination in pharmaceutical preparations was developed and validated. This method is precise, linear and sensitive. Preparation of the sample preparation is simple, does not take long, and is not solvent-consuming. The retention time of FLU is $6.0 \mathrm{~min}$ and there is no interference by excipients. The GC-FID instrument is readily available in every laboratories. Therefore, the proposed method is suitable for rutine control of the uniformity of the FLU content in pharmaceutical industry. 


\section{REFERENCES}

1. Kathawala, F. G.; Med. Res. Rev. 1991, 11, 121.

2. Mitani, H.; Kimura, M.; Cardiovasc. Drug Rev. 2000, 18, 284.

3. Farmer, J. A.; Torre-Amione, G.; Drug Saf. 2000, 23, 197.

4. Hamelin, B. A.; Turgeon, J.; Trends Pharmacol. Sci. 1998, 19, 26.

5. Broyles, F. E.; Walden, C. E.; Hunnighake, D. B.; Hill-Williams, D.; Knopp, R. H.; Am. J. Cardiol. 1995, 76, 129A.

6. Tazuma, S.; Ohya, T.; Mizuna, T.; Takizawa, I.; Kunita, T.; Takata, K.; Hayashi, K.; Hino, F.; Am. J. Cardiol. 1995, 76, A110.

7. LaRosa, J. C.; He, J.; Vupputuri, S.; J. Am. Med. Assoc. 1999, 282, 2340.

8. Nakashima, A.; Saxer, C.; Niina, M.; Masuda, N.; Iwasaki, K.; Furukawa, K.; J. Chromatogr., B 2001, 760, 17.

9. Kalafsky, G.; Smith, H. T.; Choc, M. G.; J. Chromatogr. Biomed. Appl. 1993, 614, 307.

10. Toreson, H.; Eriksson, B. M.; J. Chromatogr., A 1996, 729, 13.

11. Lanchote, V. L.; Rocha, A.; de Albuquerque, F. U. V.; Coelho, E. B.; Bonato, P. S.; J. Chromatogr., B 2001, 765, 81.

12. Al-Rawithi, S.; Hussein, R. F.; Alzahrani, A.; Ther. Drug Monit. 2003, 25,88 .

13. Nirogi, R. V. S.; Kandikere, V. N.; Shrivaslava, W.; Mudigonda, K.; Datla, P. V.; Rapid Commun. Mass Spectrom. 2006, 20, 1225.

14. Di Pietro, G.; Coelho, E. B.; Geleilete, T. M.; Marques, M. P.; Lanchote, V. L.; J. Chromatogr., B 2006, 832, 256.

15. Erk, N.; Pharmazie 2002, 57, 817.

16. Ozkan, S. A.; Uslu, B.; Anal. Bioanal. Chem. 2002, 372, 582.

17. Neves, M. M. P. S.; Nouws, H. P. A.; Delerue-Matos, C.; Anal. Lett. 2008, 41, 2794.
18. Dogrukol-Ak, D.; Kircali, K.; Tuncel, M.; Aboul-Enein, H. Y.; Biomed. Chromatogr 2001, 15, 389.

19. Turung, T. Q.; Dung, P. T.; Hoan, N. N.; Kim, D. J.; Lee, J. H.; Kim, K. H.; Arch. Pharm. Res. 2008, 31, 1066.

20. Hussein, O.; Schlezinger, S.; Rosenblat, M.; Keidar, S.; Aviram, M.; Atherosclerosis 1997, 128, 11.

21. Leonhardt, W.; Kurktschiev, T.; Meissner, D.; Lattke, P.; Abletshauser, C.; Weidinger, G.; Jaross, W.; Hanefeld, M.; Eur. J. Clin. Pharmacol. 1997, 53, 65 .

22. Bellosta, S.; Bernini, F.; Ferri, N.; Quarato, P.; Canavesi, M.; Arnaboldi, L.; Fumagalli, R.; Paoletti, R.; Corsini, A.; Atherosclerosis 1998, 137 , S101.

23. Mitani, H.; Bandoh, T.; Ishikawa, J.; Kimura, M.; Totsuka, T.; Hayashi, S.; Br. J. Pharmacol. 1996, 119, 1269.

24. Bandoh, T.; Mitani, H.; Niihashi, M.; Kusumi, Y.; Ishikawa, J.; Kimura, M.; Totsuka, T.; Isakurai, I.; Hayashi, S.; Eur. J. Clin. Pharmacol. 1996, $315,37$.

25. Leis, H. J.; Windischhofer, W.; Rapid Commun. Mass Spectrom. 2005, $19,128$.

26. Blau K.; Halket J.; Handbook of Derivatives for Chromatography, $2^{\text {nd }}$ ed., John Wiley \& Sons: New York, 1993.

27. ICH, Q2B. Harmonised tripartite guideline, validation of analytical procedure: methodology, IFPMA. In International conference on harmonization, Geneva, 1996.

28. The United States Pharmacopeia, 2006, vol. 29 (USP 29). 